\title{
SMART INSURANCE CONTRACT AGAINST POLITICAL RISKS: DEFINITIONS AND GENERAL REFLECTIONS
}

\author{
Remy Zgraggen \\ University Oldenburg, Switzerland
}

\begin{abstract}
The present research article shall outline how blockchain technology could be combined with insurance solutions against political risks. Through the definitions and the characterization of the key concepts of traditional insurance law and blockchain technology using case examples of specific political risks, it will be shown, how the insurance coverage of political risks could be achieved through smart insurance contracts in the future.
\end{abstract}

\section{Keywords}

Political Risk Insurance, Smart Insurance Contract, Blockchain, Insurance Principle, Insurance Law, Insured Event.

\section{INTRODUCTION}

\subsection{General Remarks}

Insurance can be defined as a collective risk-taking based on the insurance principle. Which means that a high number of people pay insurance premiums into a large pot and in the case of the so-called insured event they get compensation for their damages [1]. If the insured event does not occur, the insurance company keeps all the premiums. This model gives a certain incentive to the insurer to not pay claims or to deny that an insured event has occurred, in order to maximize its profits. In this context the question arises, if the collective of persons would not be able to manage the payments of the premiums and the claims themselves, without an insurance company or an insurance broker in the middle. Such a model is in general defined as a P2P insurance: individuals with similar interests pool their premiums and share a certain risk between themselves. In this way P2P insurance allows insureds to self-organize and self-administer their own insurance [2]. Within the present article some fundamental reflections shall be made how this idea could be realized through a smart insurance in the example of a political risk insurance.

\subsection{Smart Insurance Contracts in the Present Context}

For any kind of insurance there is the key question, if the insured event - which must be defined clearly and unambiguously - has occurred or not. Today the insured event is in general defined within the insurance contract between the insures and the insurance company. However, there is the possibility that the insured event is described and defined in a clear and more transparent way in a blockchain, and which leads to an automatic payment in case of realization of the insured event. Such kind of smart insurance contracts would help to remove administrative expenses at the insurance companies and speed up processes in general and remove ambiguity for the persons 
insured. However, there are various legal and economic questions and problems that need to be solved, before such a smart insurance could be implemented in practice. Questions and problems, which are in general covered and solved by the insurance company today. There is for example the question about the correct amount of the individual insurance premium in order to be able to guarantee all payments of claims for all insures in the long run in the future. And there can be the question, what will happen in a case of legal dispute between individual policyholders - for example concerning the question of responsibility for the content of the smart insurance contract in the blockchain. In addition, there are several regulatory barriers to smart insurance contracts and other Insurtech-solutions today. In practice it means for example, that it might be difficult for Insurtech providers to get the permission as a licensed insurance company by the competent supervisory authority [See 3].

The present research paper shall explore some legal or regulatory barriers for smart insurance contracts and similar blockchain-based insurance applications, especially through the example whether and under what conditions a political risk insurance could be based on a smart insurance contract. With the aim to understand the legal challenges regarding smart insurance, it is useful to outline some general key principles of insurance law first. In the second part, based on case examples, the definitions and some characteristics of political risk insurance in the context of blockchain-based smart insurance solutions shall be outlined.

\section{Principles of InSURAnCe LaW}

\subsection{Insurance Premiums as the Cost of Insurance}

The insurance premiums can be defined as the cost for the insurance - the compensation for insurance coverage by the insurance company. In other words, it is the price for the insurance contract [See 4, p. 288]. A quantification of the insurance premium is not necessary - however, a gratuitous contract (insurance coverage free of charge, without any insurance premium) cannot be considered as an insurance contract [5, p. 17]. According to legal literature the insurance premium must be at least determinable [6]. Consequently, an insurance contract can foresee for example that the insurance premium must be paid in crypto currency. This specific amount of crypto currency will be the compensation for insurance coverage. In this way it can be defined in the insurance contract that the policyholder must pay a certain number of coins at regular intervals or single one-time payment in order to receive compensation (for example a certain sum of bitcoins) in the case of occurrence of the insured event in the future. There are in general no fundamental regulatory objections against such an insurance contract. This is at least the case in the European legal framework. Even though there is a clear regulatory trend towards a more conduct-based supervision approach, which includes a review and an approval of the individual insurance product by the responsible supervisory authorities and the insurance undertakings itself through a so-called product oversight process [7]. In general, the lawfulness of an insurance product based on crypto currency under such a product oversight process will depend to a large extent on the concrete design of the underlying insurance contract, especially the contractual definition of the insured event.

\subsection{Definition of the Insured Event}

Every insurance contract must define the occurrence of the so-called insured event, which is the trigger of loss or damage for the insured. As the most common source of legal disputes between policyholders and insurance companies, the insured event must be defined clearly and in unambiguous terms within the insurance contract. The contract also defines which sum must be paid to the insured in the case of occurrence of the insured event. This can be a fixed sum (e.g. in 
the case of a life insurance) or a sum that depends on the extent of the concrete damage (e.g. in the case of a car insurance). In practice the insurance contract is often still paper-based containing the general terms and conditions of insurance (GTCI). Smart contracts- or blockchain based processes could enable cheap and fast policy management and payments, avoiding administrative costs and minimizing legal disputes. Theoretically such blockchain-based insurance contracts could be even paid in crypto currency [8]. Several blockchain-based insurance solutions already exist, such as for example "Fizzy", the smart insurance of AXA against flight delays, which is probably the first blockchain-based insurance product on the market (AXA), even though "Fizzy" is as kind of a hybrid solution between a purely blockchain-based insurance and a traditional insurance product.

\section{About a Link Between BlockChain, Traditional Insurance and Political Risk}

\subsection{Trust, Insurance and Blockchain}

In 1686, when Lloyd's was founded in a London coffee house as the first insurance company, the global insurance industry was a business of good faith, as it is still today. Therefore, a trust engine like blockchain technology is able to radically change the insurance industry while improving transparency and trust across the whole industry. A blockchain database is transparent, which means that anyone online can read it. In addition, it is a distributed database, so the information is spread among many computers around the world, making it difficult or even impossible to destroy the information. And a blockchain database resists to all subsequent manipulations of its past transactions. Finally, blockchain gives the possibility to be certain, for example when it must be defined if an insured damage happened on Sunday or on Monday [9].

In the insurance industry, but also in banking, trust is essential. The client must trust the insurance company in the way that as an insure he wants to be sure, that the damage will be covered in the case of an insured event - even when this event will happen 20 or 30 years in the future. A blockchain can potentially replace this need for trust, which is guaranteed today mainly by the insurance companies or the insurance brokers. In this way, Fintech or Insurtech solutions can allow insurance solutions where trust is guaranteed through technology instead of traditional companies. For example, a blockchain can specifically define the risk, the premium and the insured event. In the case of a damage, the compensation will then be paid automatically, without any involvement of an insurance company. At this moment this is however still a vision for a future - and products such as "Fizzy" can be considered as a starting point toward this future (See 2.2 above).

\subsection{Definitions}

\subsubsection{Fintech and Insurtech}

As the field of Fintech in general is relatively new, scientific literature is limited concerning Fintech and blockchain issues within the scientific communities of insurance and risk. Therefore, there are still broad discussions within the scientific community, how the concepts of Fintech and Insurtech can be described and defined [10, p. 3]. Insurtech can be defined as all technologies of insurance innovation, such as insurances based on artificial intelligences, smart insurance contracts and other blockchain based insurance models [11]. In this way, Insurtech companies can be defined as firms using digitalization, especially blockchain technology, for insurance solutions or insurance services [10]. Fintech can be understood as a generic term, not only covering the insurance sector, but also other sectors of the financial market, such as the banking 
or the securities market. In this way, the word Fintech can be defined as computer programs and other technologies used to support the financial industries and it combines in this way two complementary areas: financial services and solutions based on advanced technology, such as for example blockchain applications [12, p. 12]. To summarize, blockchain technology used for insurance is one element of Insurtech - it focuses on the question, how blockchain technology can be used in the insurance industry [See 13].

\subsubsection{Blockchain, Technology and Token}

Blockchain can be defined as a data protocol for non-trusted partners (with potential conflicts of interest) to collaborate and agree on the validity of transactions without anyone overseeing that process. This is a transparent process providing a distributed, digital, chronological ledger, which is immutable, shared in real time and fully auditable. At the beginning, blockchain was just a protocol that supported recording transactions in which the cryptocurrency bitcoin was being transferred between two individuals. It was needed to make sure that the origin of a bitcoin could be validated and double spending avoided in the absence of a central supervisory authority overseeing the bitcoin market. Today blockchain technology has evolved to become a protocol that allows us to record any type of transactions transferring value [14, p. $8 \mathrm{ff}$.]. Smart contracts are not necessarily blockchain-based. The term smart contract was already defined in 1996 by [15] as a "set of promises, specified in digital form, including protocols within which the parties perform on these promises" [16, p. 124]. Today however, smart contracts are often blockchainor token-based, which means that the smart contract is stored inside a blockchain, based on a specific token. A token-based blockchain system can be described as a set of information that can be clearly identified and assigned. This set of information can be in designed in different forms and take various kind of functions, such as the function of digital money such as Bitcoin. On certain systems this information is called token. The blockchain technology make sure that this information is unique and unambiguous. Through a so called public and private key, stored and created in crypto wallets, the ownership on a blockchain can be clearly defined [17, p. $124 \mathrm{f}$.]. In the following section there will be some general reflections based on case examples how a smart insurance solution against political risks could be envisaged.

\subsection{Political Risk Insurance: Possible Case Examples}

A political risk insurance contract (PRI) can be designed for example with the aim to protect policyholders against the financial consequences of a trade war between different countries, for example between China and the US or between China and Japan. Or, it is conceivable that there will be a smart insurance contract against a natural disaster or a terrorist attack in Europe. In all these examples the insured event must be described and defined in the smart insurance contract. This contract must provide a clear and unambiguous definition of the insured event. In a first step, the risk of the realization of the insured event must be defined from a legal point of view; respectively, the defining criteria for a terrorist attack, a specific natural disaster or a trade war must be found in our cases. After, this legal definition of the risk must be translated into a smart contract through a blockchain. This smart contract is then the basis for the calculation of the individual risk and consequently the amount of the premium. In this way the smart contract will clearly define if the insured event has occurred or not.

There are for example various legal possibilities to define a terrorist attack: for example, an attack can be defined as terroristic, if it has been committed by a terror group, such as for example Al Qaida or ETA. An indication for a terror attack is also the inclusion in an official and independent database, such as the Terrorism Database (https://www.start.umd.edu/gtd/) or the Global Terrorism Index (See for example the Global Terrorism Index 2017). Of course, all these criteria are to a certain extent subjective - however, as the smart contract can be consulted by 
everyone involved, it will be at any time transparent, how a terror attack, a trade war or a specific natural disaster is defined. The same principle shall apply for the calculation of the insurance premium: for example, if a country is a high-risk country concerning terrorism, such as for example Iran or Iraq, the premium calculated through the smart contract will be obviously higher, when an insured company is active in one of these countries. The risk-classification of the countries (and other parameters) must be based on criteria, such as for example the FATFcountry-list (See FATF-list on http://www.fatf-gafi.org/publications/high-riskandnoncooperativejurisdictions/). Obviously, the smart contract must be supplied with as much objective data as possible. In this way, the insurance premium will be individualized according to the risk taken, and the occurrence of the insured event will be objectified - in contrast to the situation today, where the definition of the insured event is in general within the discretion of the insurance company, especially in the case when a certain damage should be covered. Concerning the risk of a terrorist attack, the example above can also be applied on other kind of insurances, such as a simple travel insurance. In such a case, the smart contract will define, when and in which country a terrorist attack has occurred, and the contract will be able to pay out the insured sum automatically, when a flight in this country has been booked a certain timespan after the terrorist attack by the policyholder.

\section{CONCLuSive Remarks}

The way to purely blockchain-based smart insurance contracts against political risk will be a long process and can be undertaken only step by step. From a legal point of view there are barriers in private law, especially in contractual law as smart contracts cannot be considered as contracts in the legal sense, as a legal contract must be based on two corresponding declarations of intent. Therefore, an important step will be the recognition of smart contracts as generally accepted legal contracts. In public law, especially financial supervisory law, the recognition of virtual currencies for the payment of insurance premiums will be a key aspect for the future. When these barriers will be overcome, the fields of application for smart insurance contracts against political risks seem to be unlimited: every political risk, which can be legally and technically translated into a smart insurance contract, can be subject of a smart insurance contract.

\section{REFERENCES}

[1] Manes, A., Versicherungswesen, Erster Band, Allgemeine Versicherungslehre, Springer Verlag, Wiesbaden, Germany, 1922.

[2] EIOPA (European Insurance and Occupational Pensions Authority), Report on best practices on licencing requirements, P2P insurance and principle of proportionality in an InsurTech context, Frankfurt, 2018.

[3] EIOPA (European Insurance and Occupational Pensions Authority), Regulatory barriers to InsurTech in European legislation, Frankfurt, 2019.

[4] Roelli, H./Keller M./Tännler K., Kommentar zum Schweizerischen Bundesgesetz über den Versicherungsvertrag vom 2. April 1908, Bd. I: Die allgemeinen Bestimmungen, Art. 1-47, 2. Auflage, Berne, Switzerland, 1968.

[5] Kuhn, M.W., in Müller-Studer L./Eckert M.K. (Ed.), Privatversicherungsrecht - Unter Berücksichtigung des Haftpflicht- und Aufsichtrechts, Schulthess Verlag, 3. Auflage, Zurich, Switzerland, 2010.

[6] Brook, N., Insurance \& Reinsurance: Jurisdictional Comparisons, Sweet\&Maxwell, London, UK, 2012.

[7] Marano, P./Siri, M., Insurance Regulation in the European Union: Solvency II and Beyond, Springer Verlag, Wiesbaden, Germany, 2017.

[8] Gatteschi, V. et al., Blockchain and Smart Contracts for Insurance: Is the Technology Mature Enough?, in Future Internet, 10(2):20, 2018. 
[9] Gansky, L., Radical Trust: How Blockchain Liberates the Next Economy, PublicAffairs Publications, New York, US, 2018.

[10] Doulger, W., InsurTechs - Status Quo, Entwicklungslinien und Potenziale, Verlag Versicherungswirtschaft, Karlsruhe, Germany, 2016.

[11] Ricciardi, V., InsurTech Definition as its Own Manifesto, in Chishti S./Barberis J. (Ed.), The InsurTech Book, John Wiley \& Sons, Hoboken, US, 2018.

[12] Nicoletti, B., The Future of Fintech: Integrating Finance and Technology in Financial Services, Springer Verlag, Berlin, Germany, 2017.

[13] Avdeev, E., Application of the Blockchain Technology in the Insurance Industry, Universität St. Gallen, St. Gallen, Switzerland, 2018.

[14] Fraebel, Y., Die Blockchain-Technologie. Ein Überblick über die Funktionsweise, Grin-Verlag, Munich, Germany, 2018.

[15] Szabo, N., Smart Contracts: Building Blocks for Digital markets, Extropy Magazine \#16, 1996.

[16] Mukhopadhyay, M., Ethereum Smart Contract Development: Build blockchain-based decentralized applications using solidity, Packt Publishing, Birmingham, UK, 2018.

[17] Franco, P., Understanding Bitcoin: Cryptography, Engineering and Economics, Wiley \& Sons, Hoboken, 2014.

\section{AUTHORS}

\section{Remy Zgraggen}

(C) 2020 By AIRCC Publishing Corporation. This article is published under the Creative Commons Attribution (CC BY) license. 